\title{
Co-creation for Digitalization: A Study of Co-creation in Norwegian Business Clusters
}

\author{
Dag H. Olsen ${ }^{(\bowtie)}$, Tom Roar Eikebrokk, Kristian Aspø, \\ and Elaine Sajets \\ University of Agder, Kristiansand, Norway \\ \{dag.h.olsen, tom.eikebrokk\}@uia.no
}

\begin{abstract}
There is a growing emphasis on digitalization in research and business practice. The rapid progress in digital technologies compel firms to innovate and transform their businesses. One way to improve the capacity to innovate and transform is to cooperate with others. However, there is a general lack of research on how co-creation among businesses can facilitate digitalization. This qualitative study explores how co-creation among businesses can stimulate and facilitate digitalization.

We have investigated co-creation activities involving companies in business clusters. This paper reports from a study of three business clusters in Norway. We conducted an inductive qualitative study comprising semi-structured interviews as the primary empirical data source. 12 interviews were carried out with informants from three clusters. We found that the co-creation arenas and activities in the business clusters stimulate and facilitate digitalization among the cluster companies. We also addressed the most significant drivers and barriers to co-creation to get a deeper understanding of the co-creation phenomenon.
\end{abstract}

Keywords: Co-creation $\cdot$ Clusters $\cdot$ Digitalization

\section{Introduction}

Digital innovation has caused disruptive changes to the economy [1], and there is rapid change in many industries due to digitalization and digital transformation [2]. The fast progress in digital technologies generates a pressure on firms to innovate and transform their businesses. Organizations need to understand how to implement digital technologies and innovative business concepts [3]. Digitalization is very challenging for most organizations who struggle with understanding the opportunities and consequences to their business [4]. The task is especially challenging for small firms due to their general lack of resources [5]. One way to develop the capability to innovate and transform is to cooperate with others [6]. Businesses are increasingly seeking multiple partners to be more successful in applying digital solutions and achieving digitalization [7]. However, instituting and effectively managing a co-creation strategy is challenging, and potentially leading to tensions between companies [8].

Our aim has been to explore how firms can co-create with other businesses to better cope with the challenges and opportunities of digitalization. We have therefore looked for arenas where firms co-create, and we conjectured that business clusters would be 
appropriate arenas. Business clusters have some common elements of cooperation and common activities for the benefit of the cluster companies. We have therefore addressed how co-creation among businesses can contribute to digitalization among the cluster members. We thus raised the following research question: How does co-creation contribute to digitalization in business clusters? To answer this main research question, we raised three more specific research questions: What are the drivers for co-creation in the business clusters? what are the barriers for co-creation in the business clusters? and how does co-creation influence digitalization in the business clusters? By addressing the drivers for co-creation, we would improve our understanding of issues and activities that contributed to the co-creation of digitalization. By addressing the barriers for co-creation, we would get a better understanding of key issues that hampered the cocreation efforts. This would give us a deeper understanding of the how the co-creation activities addressed these issues in order to stimulate co-creation in the clusters.

The paper is organized as follows: The next sections present related work on cocreation. Then we present the research method, followed by the results and a discussion of potential implications for further research. Finally, we present the conclusion.

\section{Background}

The management literature has for many years acknowledged the significance of interdependence between enterprises, resulting in social relationships and networks [9, 10]. Such connections have provided the participants with the capacity to create opportunities for competitive advantage through new sources of information. A rising stream of research has conceptually described these collaborations as co-creation. This research can present substantial input to innovation processes [11]. These networks can enhance competitive power by forming shared sources of value creation through cocreation [12]. This collaboration is especially valuable when the market is dynamic, and the enterprises have limited resources for innovation. Firms collaborating in such networks contribute knowledge and resources in co-creating interpretations and responses. This co-creation relates to an array of corporate issues such as supply chain utilization, service innovations and of information technology implementation [13]. There is a dearth of research on the nature of co-creation in various contexts and how it can be managed $[14,15]$. There is a need for more research on issues such as how do companies that are not suppliers or customers to each other, collaborate horizontally in business networks, and how does co-creation as a dynamic process contributes to the value-creation of the enterprises and the whole ecosystem [11].

The literature has identified various factors that influences collaboration in a cluster. Lack of resources, both human and financial, can lead to hesitation among member companies when it comes to participating in innovation [6]. Trust has also been found to have a major impact on collaboration. In a case study by Sarker, Sarker, Sahaym and Bjørn-Andersen [16], the authors found that trust, goodwill and commitment are important drivers for member companies to commit resources for generating new products and services. Other findings are issues such as lack of incentives, leadership and a clear common vision. Such issues are important barriers that must be dealt with to 
create a fertile co-operation environment [6]. There are many potential benefits from co-creating, and substantial benefits can come from sharing knowledge and data [6].

Knowledge sharing is seen as the heart of collaboration and can act as a driving force for change and better understanding of customer preferences [17]. Nevertheless, it is a difficult balancing act for many companies to share their knowledge without giving up competitive advantage [18]. Furthermore, we find that increased competitiveness, increased usability of collaboration tools (if done correctly) and greater focus on customer data $[6,19]$ are advantages that can be achieved by co-creation. In SMEs, we see that IT-facilitated collaboration between companies can increase, and it can make members more proactive. It can be a challenging task to get such a collaboration going, but it can lead to improved performance [20]. In companies with few resources and employees, IT-facilitated collaboration systems can be helpful if they cooperate [6, 20], and customer loyalty and retention may increase upon establishment of such cocreation services [17]. We argue that resources are key to realize value form co-creation [21]. We therefore adopted the resource-based view (RBV) of the firm [22, 23] as an analytical lens.

Digital transformation can be defined as a major change in how business is conducted due to digital technology $[2,24,25]$. The term digitalization usually has a more limited interpretation; it is about leveraging digital technology to modify sociotechnical structures [25]. We have adopted the term digitalization, to also include minor changes to the business models. There are many definitions of digital innovation [25]. What is generally common elements is that it is perceived as something novel, and that it is based on digital technology [26, 27]. Osmundsen et al. [25] build on these definitions, and emphasizes that digital innovation is a process (to innovate) as well as an outcome, and is about "combining digital technology in new ways or with physical components that enables socio-technical changes and creates new value for adopters."

Business clusters that we know today started back in the 1950s with the production of ceramic tiles [28]. It was in a small Italian town named Sassuolo in the EmiliaRomagna area [28]. It wasn't until the early 1990s that clusters and cluster projects really came into focus through the research by Michael E. Porter [29]. This created an interest in clusters and their potential for innovation, knowledge sharing, collaboration, networking and growth [30]. Clusters can be defined as "[...] geographic concentrations of interconnected companies, specialized suppliers, service providers, firms in related industries, and associated institutions (e.g., universities, standards agencies, trade associations) in a particular field that compete but thus cooperate" [29].

We next present the research approach and the three business clusters we investigated.

\section{Research Approach and Setting}

We conducted an inductive qualitative study comprising semi-structured interviews as the primary empirical data source. 12 interviews were carried out with informants from three clusters, see Table 1 for an overview of the informants. 
Table 1. Overview over interviewees.

\begin{tabular}{l|l|l|l|l|l|l}
\hline Cluster & Informant & Position & Company size & Role in cluster & Interview date & Duration \\
\hline A & A1 & Project leader & N/A & Cluster mgmt & 02.15 .2019 & $01: 02$ \\
\hline A & A2 & Senior engineer & SME & Member company & 03.12 .2019 & $00: 58$ \\
\hline A & A3 & CTO & Large & Member company & 03.21 .2019 & $01: 08$ \\
\hline A & A4 & CEO & SME & Member company & 05.09 .2019 & $00: 54$ \\
\hline B & B1 & CEO & N/A & Cluster mgmt & 02.26 .2019 & $00: 44$ \\
\hline B & B2 & CEO & SME & Member company & 04.01 .2019 & $00: 53$ \\
\hline B & B3 & Project leader & SME & Member company & 04.11 .2019 & $00: 34$ \\
\hline B & B4 & Project leader & Large & Member company & 04.23 .2019 & $00: 35$ \\
\hline C & C1 & Member & N/A & Cluster mgmt & 04.11 .2019 & $00: 58$ \\
\hline C & C2 & CEO & SME & Member company & 04.02 .2019 & $00: 35$ \\
\hline C & C3 & CEO & SME & Member company & 04.02 .2019 & $00: 33$ \\
\hline C & C4 & Member & N/A & Cluster board & 04.02 .2019 & $00: 22$ \\
\hline
\end{tabular}

The interviews were mostly conducted face-to-face at the companies' sites. A few interviews were conducted over telephone. The interviews lasted from $22 \mathrm{~min}$ to over one hour, and they were taped and fully transcribed. The interviews were largely dialogue-based. Secondary material in the form of document studies was also utilized [31], and included information and documents available through the clusters' web pages. Due to requests for anonymity, no personal data were registered in the transcripts. The transcripts were then moved into the NVivo analysis tool. The empirical material was systematized and reduced [32], and we performed a content analysis.

Business cluster A consists of approximately 100 member companies, mainly in the energy and maritime sector. They are suppliers of technology, products and services. The cluster focuses on building competence and conducting research and training with national and international partners. The goal of the cluster is to strengthen competitiveness, improve the development of new products and services, and to apply knowledge and technology to new markets in a sustainable way. The cluster arranges and facilitates meetings, conferences and courses, in Norway as well as abroad. The cluster also runs several types of projects for cluster members.

Cluster B consists of more than 100 member companies and over 40 municipalities and other public actors. The cluster focuses on innovation, research and business development within health and welfare technology. The cluster focuses on innovation, research, development and export of products and services. Through collaboration, knowledge sharing and business development, they aim to strengthen the member companies. The cluster also aims to develop the market for health and welfare technology - both in the private and the public sector. There cluster arranges many events; it is everything from member meetings, innovation forums, conferences and courses for specific projects. They also have one innovation lab where member companies can test out various technologies.

Cluster C consists of just under 100 organizations from finance, insurance, academia and technology. The cluster focuses on financial technology, including innovation, growth and value creation. The main goal of the cluster is to make finance easy, and they work to increase export of Norwegian financial technology. The cluster 
organizes and facilitates several types of conferences, workshops and seminars - both in and outside Norway. In addition, there are many projects run by the cluster, where the idea for some of the projects has come from brainstorming events in the cluster.

\section{Results}

The interviews generated several drivers and barriers. The drivers and barriers emerged from the interview transcripts. Table 2 shows the drivers and barriers noted by the informants. An " $x$ " means that the informants agree on this issue, and an "o" means that they do not fully agree on this issue. We found that the main drivers are knowledge sharing, networking and having a proficient cluster management. The main barriers are the competition between cluster companies and the costs of cluster activities for the small member businesses.

Table 2. Drivers and barriers for digitalization.

\begin{tabular}{l|l|l|l|l|l|l|l|l|l|l|l|l}
\hline Informants: & \multicolumn{4}{|l|}{ Cluster A } & \multicolumn{4}{l|}{ Cluster B } & \multicolumn{4}{l}{ Cluster C } \\
\cline { 2 - 11 } & A1 & A2 & A3 & A4 & B1 & B2 & B3 & B4 & C1 & C2 & C3 & C4 \\
\hline
\end{tabular}

\begin{tabular}{|c|c|c|c|c|c|c|c|c|c|c|c|c|}
\hline \multicolumn{13}{|l|}{ Drivers } \\
\hline Knowledge sharing & $\mathrm{x}$ & $\mathrm{x}$ & $\mathrm{x}$ & $\mathrm{x}$ & $\mathrm{x}$ & $\mathrm{x}$ & $\mathrm{x}$ & $\mathrm{x}$ & $\mathrm{x}$ & $\mathrm{x}$ & $\mathrm{x}$ & $\mathrm{x}$ \\
\hline Networking & $\mathrm{x}$ & $\mathrm{x}$ & $\mathrm{x}$ & $\mathrm{x}$ & $\mathrm{x}$ & $\mathrm{x}$ & $\mathrm{x}$ & $\mathrm{x}$ & $\mathrm{x}$ & $\mathrm{x}$ & $\mathrm{x}$ & $\mathrm{x}$ \\
\hline Creating visibility & & & $\mathrm{x}$ & & $\mathrm{x}$ & $\mathrm{x}$ & & $\mathrm{x}$ & & & $\mathrm{x}$ & \\
\hline Access to resources & & $\mathrm{x}$ & & & $\mathrm{x}$ & & $\mathrm{x}$ & $\mathrm{x}$ & & & & \\
\hline Insight into new markets & $\mathrm{x}$ & $\mathrm{x}$ & & & $\mathrm{x}$ & & & & & & & \\
\hline Cluster management & $\mathrm{x}$ & $\mathrm{x}$ & & $\mathrm{x}$ & & $\mathrm{x}$ & $\mathrm{x}$ & & $\mathrm{x}$ & $\mathrm{x}$ & & \\
\hline \multicolumn{13}{|l|}{ Barriers } \\
\hline Time & & $\mathrm{x}$ & $\mathrm{x}$ & & & $\mathrm{x}$ & & $\mathrm{x}$ & $\mathrm{x}$ & $\mathrm{x}$ & $\mathrm{x}$ & \\
\hline Costs & $\mathrm{x}$ & & o & $\mathrm{x}$ & o & o & 0 & $\mathrm{x}$ & 0 & & $\mathrm{x}$ & \\
\hline Competition & $\mathrm{x}$ & & $\mathrm{x}$ & & $\mathrm{x}$ & $\mathrm{x}$ & $\mathrm{x}$ & $\mathrm{x}$ & $\mathrm{x}$ & & & \\
\hline Little activity & & $\mathrm{x}$ & & & $\mathrm{x}$ & & & $\mathrm{x}$ & $\mathrm{x}$ & & & $\mathrm{X}$ \\
\hline
\end{tabular}

The informants from the three clusters had similar conceptions of the term digitalization. A common element among informants from cluster A was that digitalization is about employing technology to make "things simpler", for example making information more accessible. Informant A2 noted that the industry is quite conservative, making it difficult to get support for disruptive changes. Two of the informants in cluster A viewed digitalization as primarily the application of existing technologies. The focus was thus on improving rather than replacing. Informant A2 provided the following examples: automated monitoring of windmills and automated monitoring of maintenance requirements. This would be through sensors to monitor and report. Informant A1 noted that "the technology in itself is not important; it is what you can do with it for the business." Informant A1 further commented that a recent report found that enterprises with 10 to 250 employees struggle the most with digitalization - "they are big enough to make it complicated, but do not have the resources needed." 
All informants in cluster B had an almost equal view of digitalization, what it implies and what opportunities this may entail in the flow of information. It was perceived to be about how to use data or digital tools to improve processes, automate processes and get different systems for talking together. Informant B2 noted that their perception of digitization depends on the context. Within the enterprise, digitization focuses on the collection and use of data to improve various health indicators among patients. Beyond this, they pointed out that they are working to make municipalities understand "how the digital data makes it much easier for them to understand things". Informant B4 corroborated this view, and he emphasized that digitalization meant "[...] how can we improve efficiency and work smarter". It was further observed that digitization was also important for management in terms of change management. Informant B1 stated that "Digital tools or digital technology give you other opportunities to do things in a completely different way." Informant B1 brought up the term disruptive as a key word for "new ways to operate your [company] that new technology enables," and pointed out that digitalization has top priority in the health sector.

Informants from cluster $\mathrm{C}$ emphasized process automation and application of technology as key digitalization matters. Informant $\mathrm{C} 1$ noted that digitalization is about "how technology can be used for a good user experience [...] That's the key." Informant $\mathrm{C} 4$ from the cluster management also viewed customer experiences as the main focus. However, informant $\mathrm{C} 4$ emphasized that they need a precise definition. Informant $\mathrm{C} 4$ explained that "You have quite a few options then, with computing power and sensors and digital tools, to solve tasks that people had to solve [before]. That's probably the big picture digitization for me." Informant C2 explained that "Within our industry, digitalization is about creating, often moving certain tasks that have been manual over to smartphones, so that consumers can access it in better way. So, yes, it is really there to facilitate everyday life and optimize and automate processes to a large extent."

The interviews showed that the three clusters have several arenas for co-creation. The informants from cluster A emphasized arenas such as workshops, conferences, courses and co-creation projects. The project manager from the cluster administration estimated that they currently had approximately 30 cluster projects, either ongoing or about to start. Two of the informants from this cluster emphasized a test laboratory that they sponsor, where a university is the main owner. This is a lab where the cluster holds workshops with member companies, where they are exposed to emerging technologies, such as AR, VR and 3D printing. This has been seen a way to extend the member companies' scope outside the oil and gas industry. Informant A3 noted that "Then one realizes that many of these companies needed such a test lab. Then it was no longer a one-sided focus on drilling and oil exploration, it was a [quite] broader [focus]." Several informants underlined that the oil and gas industry is very conservative, and that it was very beneficial that the member companies were exposed to opportunities and challenges related to new technology. Informant A1 noted that "We also have workshops on strategy and business development [...]. How will the new digital technology influence [the cluster companies]? What do they need to do today to [be] where they want to be 5 to 10 years [from now]?" We see from these examples that this 
cluster has many co-creation activities that encourage and support digitalization efforts among cluster companies. Table 3 shows which co-creation arenas was noted by the informants.

The informants from cluster B would use terms like building relationships and networks, and raising competencies and innovation, when describing the cluster activities. The cluster has focus on creating programs that would be beneficial for the members, efforts to raise competencies among members, arranging co-creation projects and fundraising. This cluster focuses on health technology, and it has therefore a strong relationship to the public sector, since this marked is dominated by the public healthcare system. Informant B1 asserted that: "[...] since it is about health [technology] in the public sector, we need to [focus on] developing the market too. It is quite immature. [...] We work quite a lot with developing the Norwegian health industry." Informant B2 corroborated this, and he added that "[...] having the local municipalities as members meant quite a lot, since then we had a sparring partner we could learn from." We therefore conclude that the co-creation activities in this cluster clearly promotes digitalization among cluster companies.

Table 3. Co-creation arenas noted.

\begin{tabular}{l|l|l|l|l|l|l|l|l|l|l|l|l}
\hline & \multicolumn{4}{l}{ Cluster A } & \multicolumn{4}{l|}{ Cluster B } & \multicolumn{4}{l}{ Cluster C } \\
& A1 & A2 & A3 & A4 & B1 & B2 & B3 & B4 & C1 & C2 & C3 & C4 \\
\hline Hackatons & x & & & & & & & & x & & & x \\
\hline Conferences & x & x & x & & x & x & x & x & x & x & x & \\
\hline Courses & x & x & & & x & x & & x & x & x & & x \\
\hline Digitalization Lab. & x & & x & & x & x & x & x & & & & \\
\hline Seminars & x & & & & & & & x & & x & & \\
\hline Brainstorming sessions & x & x & & & x & x & & x & x & & x & \\
\hline
\end{tabular}

The informants from cluster $\mathrm{C}$ emphasized activities stimulating co-creation such as networking and knowledge sharing. Informant $\mathrm{C} 1$ noted that the cluster facilitates travels to industry conferences and gathers members for joint travels: "they dine together, have breakfast together, they attend [conference sessions] together, so [they] become good friends. [Networks] are made there". This contributes to stronger ties between people in the cluster, and it creates a stronger cluster identity and a network between people in the cluster companies. All informants emphasized the importance of networking activities for gaining deeper understanding of the challenges and opportunities related to digitalization. Informant C2 noted that they have found a business partner (in the cluster) that is proficient on machine learning, through the cluster networking activities. Informant 3 pointed out the importance of being visible in the cluster, and that the network they get access to, is very interesting, and described that this is an "investment in the future". We therefore find that significant co-creation activities were aimed at improving digital competencies and skills among cluster companies, and thus to the digitalization of these companies. 


\section{Discussion}

We have explored how co-creation contributes to digitalization in three Norwegian business clusters. We found that co-creation is an important vehicle for digitalization among the individual member companies. By addressing the drivers and barriers for co-creation, we were able to achieve a better understanding of co-creation as a phenomenon, how co-creation manifests itself and the important factors related to achieving co-creation in practice. We will elaborate on the various factors below.

We conjectured that three drivers were particularly significant for achieving cocreation in the clusters. First, networking activities were perceived as a major driver for co-creation. This is consistent with the literature on business clusters (e.g. [33]), which views network building as one of the most common cluster goals. All informants in the three cases emphasized this as one of the main drivers for membership. Some companies joined the cluster to get access to new customers or partners, while others saw the cluster as an opportunity to develop new competences and capabilities. Regardless of the corporate intention, the clusters arrange various activities that facilitate networking among the members. We conjecture that such activities were essential to create arenas for co-creation. These activities could be reserved for cluster members, or they could include public institutions outside the cluster as well as members of other clusters. This is also consistent with Porter's [29] finding that involving and activating cluster members of all sizes is important for collaboration and community.

Second, related to this, we found that knowledge sharing was also a major driver for co-creation. The companies see clusters as a place to go to meet other companies in an informal setting. Informal arrangements like this have proven to lead to friendship which is important when it comes to building trust [34]. When the members of a cluster increase their trust in each other it can lead to more knowledge sharing. Networking activities create relationships and build trust between companies. This can create an arena for exchanging knowledge and experience among the cluster members. This is consistent with the literature, which points out that knowledge exchange is central in collaboration [6], and a driving force for change [17]. In our literature review, we uncovered two activities related to knowledge sharing that is consistent with our findings [35]:

- Co-inform: Common to all three clusters is the newsletter that the cluster management sends out to the cluster members by email. The newsletters convey activities and opportunities in the cluster, as well as providing information on ongoing and new projects. They also have websites where, among other things, they present the cluster members.

- Co-learn: Both Cluster A and Cluster B offer their members access to a test lab where they can access technology that they might not otherwise be able to afford. Such labs are important for companies, regardless of available resources, to test new technological trends and get access to useful knowledge. In this way they may get the ability to identify appropriate technology. Research has demonstrated that testing out new technological trends is important in order to further develop your business processes [33], and that digital technology can have a direct impact on how businesses innovate [1]. 
Third, we also found that cluster management was also an important driver. Many of the respondents emphasized that it was easy to get access to the cluster management. This made it easy take initiatives, for example to make request for training or to propose topics for cluster seminars. We therefore conjecture that a strong cluster management is important for initiating and supporting co-creation activities.

We identified two significant barriers. First, competition among the members is a significant barrier. We saw that informants generally are positive to sharing competence, but also that a majority of them are hesitant to share strategies or concepts where time to market is an issue. The literature also emphasizes the perils of sharing knowledge with competitors, and it may relinquish competitive advantage [18].

Second, most informants did not perceive membership costs as a significant problem, especially informants from large enterprises. However, the informants that believed that costs was an issues, felt that there should not be a membership fees for small businesses. Also, several informants from small enterprises noted that the costs of participating in cluster activities was sometimes prohibiting small member companies from participating. This is consistent with the literature, which has demonstrated that limited human and economic resources can be a significant challenge for co-creation [6]. Several informants noted that the projects could last a long time, and this would reduce the interest among the participants. The longer the time between the workshops, the higher the likelihood would be of members withdrawing from a project [25].

The activities in clusters are usually based on input from its members. Most informants noted that it was easy to get access to the cluster management, and that it was easy to propose topics for activities or projects in the clusters. It was generally perceived that it was a short way from proposing a new topic to set up a project through a brainstorming session. This can lead to digital innovation through the co-creation of new products or services [15, 25]. This supports the argument that clusters drive innovation. Sölvell et al. [33] argue that there are three critical arguments for why innovation tend to be connected with clusters: (1) the need for incremental reduction of technical and economic uncertainty, (2) the need for repeated and continuous interaction between related firms and specialized institutions (including research and education), and (3) The need for face-to-face contact in the exchange and creation of new knowledge. Our findings demonstrated that the three clusters in this study facilitate resolution of all those needs.

We saw that the clusters offered the members arenas where co-creation processes could take place. The clusters would arrange brainstorming events where members from various topical areas could discuss ideas and solutions related to perceived market needs, facilitate co-creation projects, and aid in the application for external funding. Such processes were vital to stimulate co-creation of digital innovation and digitalization in all three clusters.

Based on the findings and the discussion above, we argue that co-creation can be an important avenue for digitalization, digital innovation or digital transformation of companies. We contend that this is particularly true for the companies that have limited human and financial resources, such as small and medium sized enterprises. Such companies have limited resources to implement digital technologies and innovative business concepts. We therefore see co-creation arenas, such as business clusters, as beneficial for the digitalization of such companies. 


\section{Conclusion}

This study has explored how co-creation can contribute to digitalization among companies in business clusters. We found that the co-creation arenas and activities within the business clusters stimulate and facilitate digitalization among the cluster companies. The study also addressed the most significant drivers and barriers to co-creation to get a deeper understanding of the co-creation phenomenon. Co-creation arenas, such as business clusters, can be very valuable for companies that do not have substantial resources to devote to innovation activities, such as digitalization and digital transformation.

This research has several limitations. It was performed in three clusters with a small number of informants and, therefore, has limited generalizability. Further research should explore this pertinent issue in other contexts, using the present research as a basis for subsequent quantitative studies to provide generalizable results. Such results can contribute to a better understanding about how organizations can co-create with other organizations in order to innovate and transform, and thus contributing to the theory on co-creation. This will be particularly beneficial for resource poor organizations, such as small and medium sized enterprises.

\section{References}

1. Yoo, Y.: The tables have turned: how can the information systems field contribute to technology and innovation management research? J. Assoc. Inf. Syst. 14(5), 227-236 (2012)

2. Hartl, E., Hess, T.: IT projects in digital transformation: a socio-technical journey towards technochange. In: Proceedings of the 27th European Conference on Information Systems, AIS Electronic Library, Stockhom-Uppsala (2019)

3. Stief, S.E., Eidhoff, A.T., Voeth, M.: Transform to succeed: an empirical analysis of digital transformation in firms. World Acad. Sci. Eng. Technol. Int. J. Soc. Behav. Educ. Econ. Bus. Ind. Eng. 10(6), 1833-1842 (2016)

4. Bharadwaj, A., El Sawy, O.A., Pavlou, P.A., Venkatraman, N.: Digital business strategy: toward a next generation of insights. MIS Q. 37(2), 471-482 (2013)

5. Zach, O., Munkvold, B.E., Olsen, D.H.: ERP system implementation in SMEs: exploring the influences of the SME context. Enterp. Inf. Syst. 8(2), 309-335 (2014)

6. Eikebrokk, T.R., Lind, E., Olsen, D.H.: Co-creation of IT-value in a cluster of small enterprises. Procedia Comput. Sci. 138, 492-499 (2018)

7. Grover, V., Kohli, R.: Cocreating IT value: new capabilities and metrics for multifirm environments. MIS Q. 36(1), 225-232 (2012)

8. Gnyawali, D.R., Park, B.-J.R.: Co-opetition between giants: collaboration with competitors for technological innovation. Res. Policy 40(5), 650-663 (2011)

9. Czakon, W., Kawa, A.: Network myopia: an empirical study of network perception. Ind. Mark. Manag. 73, 116-124 (2018)

10. Grönroos, C., Voima, P.: Critical service logic: making sense of value creation and cocreation. J. Acad. Mark. Sci. 41(2), 133-150 (2013). https://doi.org/10.1007/s11747-0120308-3

11. Nambisan, S.: Designing virtual customer environments for new product development: toward a theory. Acad. Manag. Rev. 27(3), 392-413 (2002) 
12. Prahalad, C.K., Ramaswamy, V.: Co-creation experiences: the next practice in value creation. J. Interact. Mark. 18(3), 5-14 (2004)

13. Kohlbacher, F.: International Marketing in the Network Economy: A Knowledge-Based Approach. Palgrave Macmillan, Basingstoke (2007)

14. Felzensztein, C., Gimmon, E., Deans, K.R.: Coopetition in regional clusters: keep calm and expect unexpected changes. Ind. Mark. Manag. 69, 116-124 (2018)

15. Frow, P., Nenonen, S., Payne, A., Storbacka, K.: Managing co-creation design: a strategic approach to innovation. Br. J. Manag. 26(3), 463-483 (2015)

16. Sarker, S., Sarker, S., Sahaym, A., Bjørn-Andersen, N.: Exploring value cocreation in relationships between an ERP vendor and its partners: a revelatory case study. MIS Q. 36(1), 317-338 (2012)

17. Zainuddin, E., Gonzalez, P.: Configurability, maturity, and value co-creation in SaaS: an exploratory case study. In: Proceedings of the 32nd International Conference in Information Systems (ICIS), AIS Electronic Library (2011)

18. Yoong, P., Molina, M.: Knowledge sharing and business clusters. In: Proceedings of the Pacific Asian Conference on Information Systems (PACIS), AIS Electronic Library (2003)

19. Giesbrecht, T., Schwabe, G., Schenk, B.: Service encounter thinklets: how to empower service agents to put value co-creation into practice. Inf. Syst. J. 27(2), 171-196 (2017)

20. Chang, H.-L., Chou, C.-Y.: Shaping proactivity for firm performance: evaluating the role of it-enabled collaboration in small and medium enterprises. In: Proceedings of the Pacific Asian Conference on Information Systems (PACIS), AIS Electronic Library (2012)

21. Schryen, G.: Revisiting IS business value research: what we already know, what we still need to know, and how we can get there. Eur. J. Inf. Syst. 22(2), 139-169 (2013)

22. Barney, J.B.: Firm resources and sustained competitive advantage. Adv. Strat. Manag. 17, 203-227 (2000)

23. Mata, F.J., Fuerst, W.L., Barney, J.B.: Information technology and sustained competitive advantage: a resource-based analysis. MIS Q. 19(4), 487-505 (1995)

24. Bilgeri, D., Wortmann, F., Fleisch, E.: How digital transformation affects large manufacturing companies' organization. In: Proceedings of the 38th International Conference in Information Systems (ICIS), AIS Electronic Library (2017)

25. Osmundsen, K., Iden, J., Bygstad, B.: Digital transformation: drivers, success factors and implications. In: Proceedings of the 12th Mediterranean Conference on Information Systems (MCIS), AIS Electronic Library (2018)

26. Fichman, R.G., Dos Santos, B.L., Zheng, Z.E.: Digital innovation as a fundamental and powerful concept in the information systems curriculum. MIS Q. 38(2), 329-354 (2014)

27. Yoo, Y., Henfridsson, O., Lyytinen, K.: Research commentary-the new organizing logic of digital innovation: an agenda for information systems research. Inf. Syst. Res. 21(4), 724735 (2010)

28. Porter, M.E.: Clusters and the new economics of competition. Harvard Bus. Rev. 76(6), 77$90(1998)$

29. Porter, M.E.: Location, competition, and economic development: local clusters in a global economy. Econ. Dev. Q. 14(1), 15-34 (2000)

30. Malmberg, A., Power, D.: True clusters: a severe case of conceptual headache. In: Asheim, B., Cooke, P., Martin, R. (eds.) Clusters and Regional Development, pp. 68-86. Taylor \& Francis Group (2006)

31. Myers, M.D., Newman, M.: The qualitative interview in IS research: examining the craft. Inf. Organ. 17(1), 2-26 (2007)

32. Miles, M.B., Huberman, A.M.: Qualitative Data Analysis: An Expanded Sourcebook. Sage, Thousand Oaks (1994) 
33. Sölvell, Ö., Lindqvist, G., Ketels, C.: The Cluster Initiative Greenbook. Ivory Tower, Stockholm (2003)

34. Bergh, P., Thorgren, S., Wincent, J.: Entrepreneurs learning together: the importance of building trust for learning and exploiting business opportunities. Int. Entrep. Manag. J. 7(1), 17-37 (2011). https://doi.org/10.1007/s11365-009-0120-9

35. Waits, M.J.: The added value of the industry cluster approach to economic analysis, strategy development, and service delivery. Econ. Dev. Q. 14(1), 35-50 (2000) 